\title{
The Thermal Expansion of 3C-SiC in TRISO particles by High Temperature X-ray Diffraction
}

\author{
Noko Ngoepe ${ }^{\mathrm{a}}$, Johan de Villiers ${ }^{\mathrm{a}}$ \\ ${ }^{a}$ Department of Materials Science and Metallurgical Engineering, University of Pretoria
}

\begin{abstract}
The lattice parameter change of $\mathrm{SiC}$ in TRISO particles prepared by chemical vapour deposition (CVD) was measured using high temperature $\mathrm{X}$-ray diffraction, across a temperature range of 25 to $1400^{\circ} \mathrm{C}$. $\mathrm{Al}_{2} \mathrm{O}_{3}$ was used as the internal standard and the $\mathrm{SiC}$ temperature corrections were calibrated using its two independent lattice parameter values along the a- and c-axes. Experimental unit cell values of $\mathrm{SiC}$ at low temperatures corresponded well with those published in previous literature, but deviated systematically at higher temperatures. Thermal expansion coefficients of the CVD prepared SiC shell material are considered the most accurate and follow a linear trend with increasing temperature $\left(\alpha_{11}=\right.$ $\left.2.7706 \times 10^{-9} \mathrm{~T}+3.3048 \times 10^{-6} \mathrm{~K}^{-1}\right)$. The TRISO particles are described best using non-linear expansion coefficients. Apparent is the deviation in the SiC lattice constants of the shell material and the TRISO particles from which it originated. This could indicate a residual strain in the TRISO particles or a difference in sample displacement between the TRISO particles and the surrounding alumina standard. The room temperature lattice constant for the shell material is $4.36030 \AA$ (SD $0.00006 \AA$ ) as compared with that of the TRISO sample of $4.35835 \AA$ (SD $0.00006 \AA$ ) after adjusting the sample displacement to get alumina lattice constants as close to the accepted values. Residual stress of $\sim 300 \mathrm{MPa}$ is calculated from the lattice constant differences.
\end{abstract}

Keywords: SiC, Thermal expansion, TRISO, X-ray diffraction

\section{Introduction}

Tri-structural isotropic (TRISO) coated nuclear fuel particles consist of a micro-spherical kernel of uranium oxide or oxycarbide fuel and coating layers. These consist of a porous pyrolytic carbon (PyC) layer, the inner PyC (IPyC) carbon layer, a silicon carbide (SiC) layer, and an outer PyC (OPyC) carbon layer. The function of the coating layers is to retain fission products within the particle [1]. Figure 1 illustrates these layers schematically. The low density porous PyC coating layer is called the buffer layer (about $50 \%$ void) and attenuates fission recoils and provides void volume for gaseous fission products as well as carbon monoxide. It also accommodates kernel swelling without transmitting forces to the outer coatings. The high density, isotropic IPyC coating layer contains the fission products and carbon monoxide during irradiation, protects the kernel from reactions with chlorine during $\mathrm{SiC}$ deposition and provides structural support for the $\mathrm{SiC}$ layer. The $\mathrm{SiC}$ coating layer provides the mechanical strength to withstand stresses from internal gas pressure build up and other sources. Secondly, it acts as a barrier to high pressure diffusion of gaseous and metallic fission products generated in the kernel/buffer region, which can diffuse through the IPyC layer. The function of the high density OPyC layer is to protect the SiC during the remainder 
of the fabrication process and to provide structural stability to the $\mathrm{SiC}$ coating during irradiation [1-2]. All the layers are deposited using a chemical vapour deposition (CVD) technique.

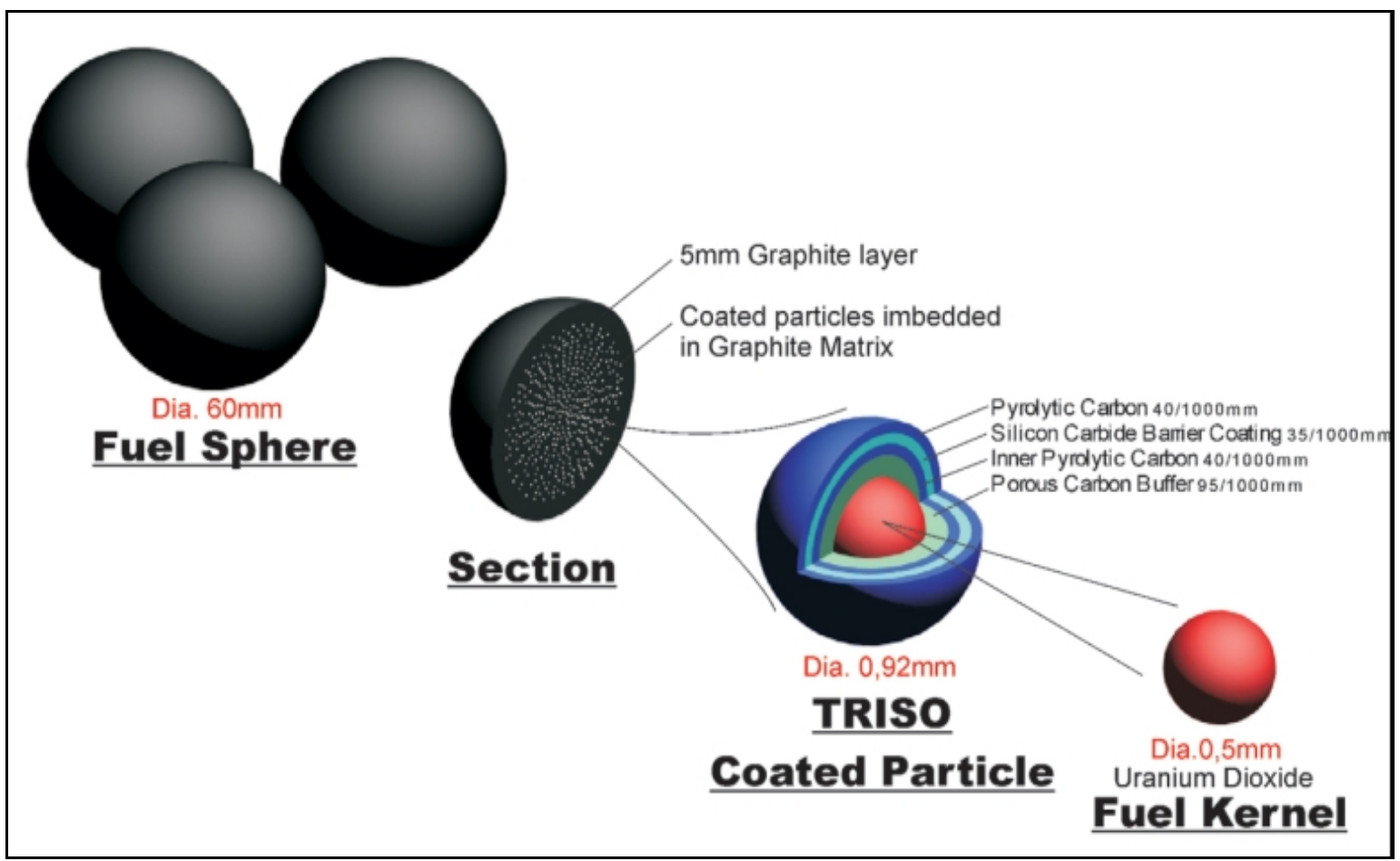

Figure 1 - Schematic diagram of TRISO particles and the respective layer thicknesses [3].

$\mathrm{SiC}$ has a very high thermal stability. It is not possible to melt it at atmospheric pressure as it sublimes and dissociates into $\mathrm{C}$ and $\mathrm{Si}$-rich vapour [4]. The thermal expansion behaviour of $\mathrm{SiC}$ has been studied with x-ray diffraction [5-9], interferometry [10] and dilatometry [1112], as is summarized in Table 1. Average thermal expansion coefficient values of 4.3 to $6.2 \times 10^{-6} \mathrm{~K}^{-1}$ have been reported. The reader is referred to the paper by Li and Bradt [5] for a graphical comparison of the expansion coefficients from the different authors.

\begin{tabular}{|c|c|c|c|}
\hline Author & Technique & $\begin{array}{c}\text { Temperature } \\
\text { range (K) }\end{array}$ & $\bar{\alpha}\left(\mathbf{1 0}^{-\mathbf{6}} \mathbf{K}^{-\mathbf{1}}\right)$ \\
\hline Li and Bradt [5] & XRD & RT - 1273 & 4.45 \\
\hline Becker [6] & XRD & RT - 1473 & 6.2 \\
\hline Taylor and Jones [7] & XRD & RT - 1473 & 4.4 \\
\hline Clark and Knight [8] & XRD & RT - 1473 & 4.5 \\
\hline Suzuki et al. [9] & XRD & RT - 1173 & 4.3 \\
\hline Pojur et al. [10] & Interferometer & RT - 780 & 4.38 \\
\hline $\begin{array}{c}\text { Popper and } \\
\text { Mohyuddin [11] }\end{array}$ & Dilatometer & RT - 1673 & 4.4 \\
\hline Price [12] & Dilatometer & RT - 1273 & 4.94 \\
\hline
\end{tabular}

Table 1 - Average thermal expansion coefficients of 3C-SiC (Adapted from Snead et al. [2])

The present study was undertaken to establish whether differences exist between the thermal expansion behaviour of $\mathrm{SiC}$ in untreated as-manufactured TRISO coated particles and samples prepared by different methods, as reported in the literature. More specifically, 
residual stress in TRISO particles has been reported by Niihara [13] as well as by Lu and Leu [14]. This residual stress should be manifested as a change in the SiC lattice constant.

\section{Samples}

The following samples were analysed by high temperature X-ray diffraction. They are given in Table 2, together with the heating element and the temperature ranges used in the experiments. All samples consist of CVD prepared SiC. Sample CR14-UP was prepared in the UP CVD coating unit, whereas the others were obtained from the PBMR company. Part of sample CR14 was crushed and its $\mathrm{SiC}$ shells separated from the rest of the constituents. This was then ground together with the alumina internal standard and used as a reference material since the residual stress should be relieved by the crushing and grinding action.

Table 2. Sample properties used in the experiments.

\begin{tabular}{|l|l|l|l|}
\hline Sample & Type & Heating element & Temperature Range \\
\hline 1. CR14-UP & Ground SiC shell & Graphite/AlN holder & $25-1200^{\circ} \mathrm{C}$ \\
\hline 2. CR14-UP & TRISO particles & Graphite/AlN holder & $25-1200^{\circ} \mathrm{C}$ \\
\hline 3. G102 & TRISO particles & Molybdenum heat strip & $25-1400^{\circ} \mathrm{C}$ \\
\hline 4. PO4 & TRISO particles & Graphite/AlN holder & $25-1400^{\circ} \mathrm{C}$ \\
\hline 5. PO9 & TRISO particles & Graphite/AlN holder & $25-1400^{\circ} \mathrm{C}$ \\
\hline
\end{tabular}

Sample CR 14-UP was prepared in a spouted bed coater that was designed and built at the University of Pretoria. The deposition temperature was $1550^{\circ} \mathrm{C}$. The MTS percentage was set at $1.5 \%$, with an actual value of $1.64 \%$. The hydrogen flow rate was set at 12.5 liters/minute, while the actual flow was 12.1 liters/minute.

\section{Experimental Methods}

The XRD patterns of all samples were obtained using a PANalytical X'Pert Pro powder diffractometer with $\mathrm{CoK}_{\alpha}$ radiation $(\lambda=1.78901 \AA)$, fitted with an Anton Paar HTTK 1600 XRD furnace. The heating programme was integrated with the XRD measurements by the diffractometer measurement programme. No monochromator was used. The generator settings used are $35 \mathrm{kV}$ and $50 \mathrm{~mA}$. The analyses were performed across an angular range

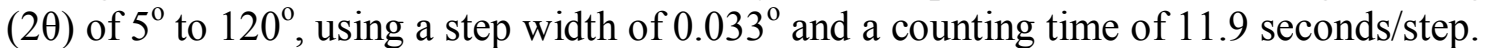
The as-manufactured TRISO particles were deposited on a heating strip or ALN sample holder by $\mathrm{Al}_{2} \mathrm{O}_{3}$ cement (ground using mortar and pestle mixed with ethanol). Samples CR14-UP, PO4 and PO9 were analyzed with a graphite heating strip with $99.99 \%$ pure nitrogen. Sample G102 was analyzed using a molybdenum heating strip with helium as the inert gas. The displacement of the particles from the instrument focus position of samples 1 and 2 (CR14-UP) was purposely adjusted to approach the room temperature unit cell dimensions of alumina as close as possible to literature values. For the other samples, the initial displacement was less accurately adjusted,

Starting from room temperature $\left(25^{\circ} \mathrm{C}\right)$, the temperature increments were variable for the different samples, but usually in steps of $100^{\circ}$. Upon cooling, the steps were also variable, and in some samples, cooling from $1100^{\circ} \mathrm{C}$ to $25^{\circ} \mathrm{C}$ was done in a single step. Each sample was held at the desired temperature for 5 minutes before XRD analysis commenced. The Rietveld method using the TOPAS [15] software package was used to refine the lattice parameters by updating each next step with the parameters determined in the previous step. A 
sample displacement correction was done for each determination to correct for the effect of thermal expansion of the heating strips at higher temperatures.

\section{Results and discussion}

The results quoted are the result of the use of Rietveld analysis of $\mathrm{SiC}$ admixed with alumina as internal standard to eliminate the effects of sample displacement and other systematic errors that could affect the determination of accurate lattice constants of $\mathrm{SiC}$ at various temperatures. Rietveld analysis, which uses the entire diffraction pattern, provides lattice parameters of high accuracy, and should in principle give accurate linear expansion coefficients.

The analysis of $\mathrm{Al}_{2} \mathrm{O}_{3}$ is important because it provides an internal standard for correcting the sample temperatures, since they differ from the instrument set point temperatures due to thermal gradients in the sample holders and due to heat losses in the instrument. The a-axis and c-axis measurements of $\mathrm{Al}_{2} \mathrm{O}_{3}$ therefore provide an independent measure for calibrating sample temperatures, and as a consequence, also the a-lattice parameters of SiC.

Figure 2 shows the diffraction pattern of sample CR14-UP shell material in the high temperature instrument. Refinement of this sample gives good accuracy and precision after initial adjustment of the sample displacement. The Rwp refined to $7.9 \%$ with lattice parameters of alumina (standard deviation in parentheses); $\mathrm{a}=4.75926(0.00003) \AA$ and $\mathrm{c}=$ $12.99216(0.00008) \AA$ which compares with the NIST values for SRM676a of a $=4.75909$ $(0.00001) \AA$ and $\mathrm{c}=12.99177(0.00003) \AA$. The $\mathrm{SiC}$ refined to $\mathrm{a}=4.36030(0.00005) \AA$. The sample displacement did not refine significantly from the zero position with a standard deviation of $0.06 \mathrm{~mm}$. The corresponding values for the lattice constants using the coefficients given by Touloukian [16] at $25^{\circ} \mathrm{C}$ are $\mathrm{a}=4.75892 \AA$ and $\mathrm{c}=12.99327 \AA$.

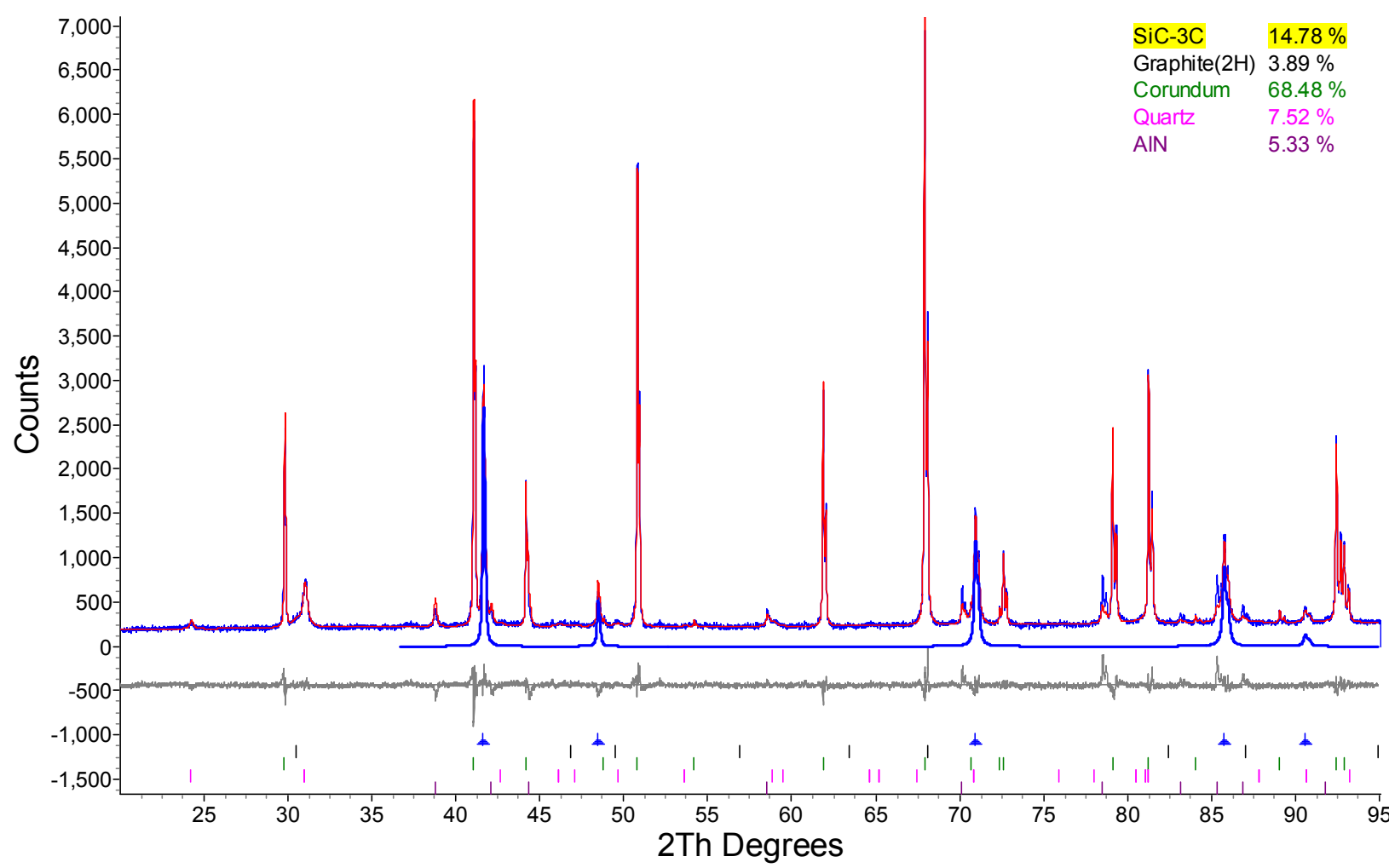

Figure 2. Refined XRD pattern of sample CR14-UP shell material mixed with alumina at $25^{\circ} \mathrm{C}$. Four phases, SiC-3C, alumina, minor graphite and quartz, and AlN (sample holder) 
were refined. The curve for the $\mathrm{SiC}$ component is shown, and the difference curve is also indicated.

Figure 3 shows the a-lattice parameters of $\mathrm{Al}_{2} \mathrm{O}_{3}$ with temperature in the first 3 samples as compared to the values calculated from the polynomial given by Touloukian [16]. From a correspondence at room temperature, the lattice parameters deviate increasingly at higher temperatures mainly because of increased heat losses and poor heat conduction from the heating strip to the sample via the sample holder in samples 1 and 2. With sample G102, poor thermo couple adhesion to the molybdenum heating strip became apparent at the high temperature. Using the calculated unit cell values of alumina, the temperatures will be recalculated and the calibrated temperatures will be used for the calculation of the $\mathrm{SiC}$ lattice constants.

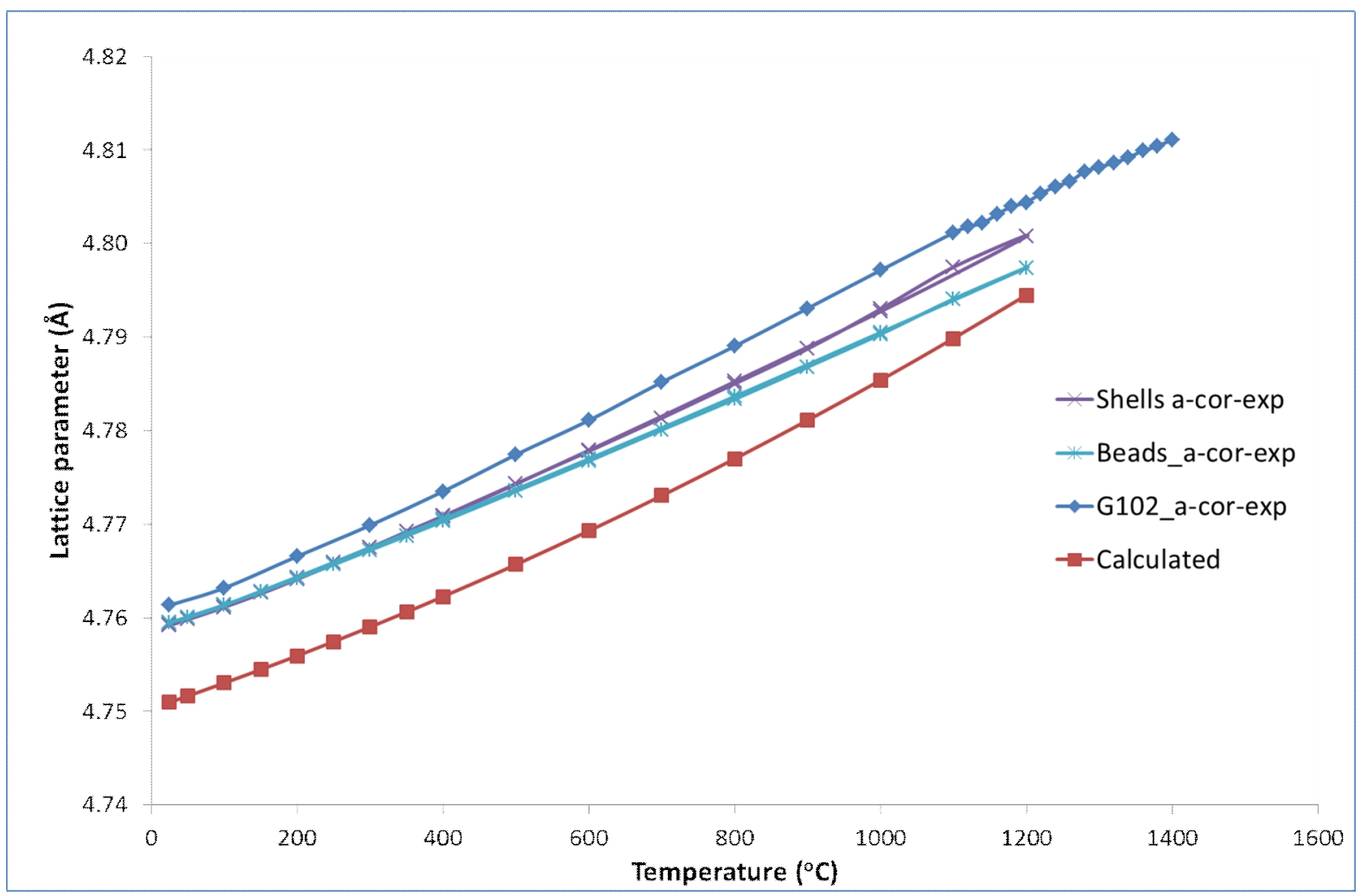

Figure 3. Variation of the a-lattice parameter of alumina at increasing temperatures in comparison to the values calculated using the polynomial by Touloukian [16].

The equation of the a-axis expansion of $\mathrm{Al}_{2} \mathrm{O}_{3}$ used in this study is given by the polynomial:

$a(T)=4.75814\left(1+6.55 \times 10^{-6} T+1.82 \times 10^{-9} T^{2}\right) \quad$ with $T$ in ${ }^{\circ} \mathrm{C}$

The equation of the c-axis expansion is:

$c(T)=12.99113\left(1+6.54 \times 10^{-6} T+2.60 \times 10^{-9} T^{2}\right) \quad$ with $T$ in ${ }^{\circ} \mathrm{C}$

The results of the first three samples are given separately as their results are more consistent and considered to be more accurate than the last two, which will be also be included because of their higher temperature range. 
The lattice constant expansion of $\mathrm{SiC}$ with temperature for samples 1 to 3 is given in Figure 4. The curves were constructed after separate temperature correction with both the a-axis and c-axis data of alumina and also include both heating and cooling data. Apparent is the consistency of the data and the correspondence of the curves of samples 2 and 3. Also apparent is the difference in the corrected room temperature $\mathrm{SiC}$ lattice constants between the separated, ground up shell material and the TRISO particles of the same sample batch.

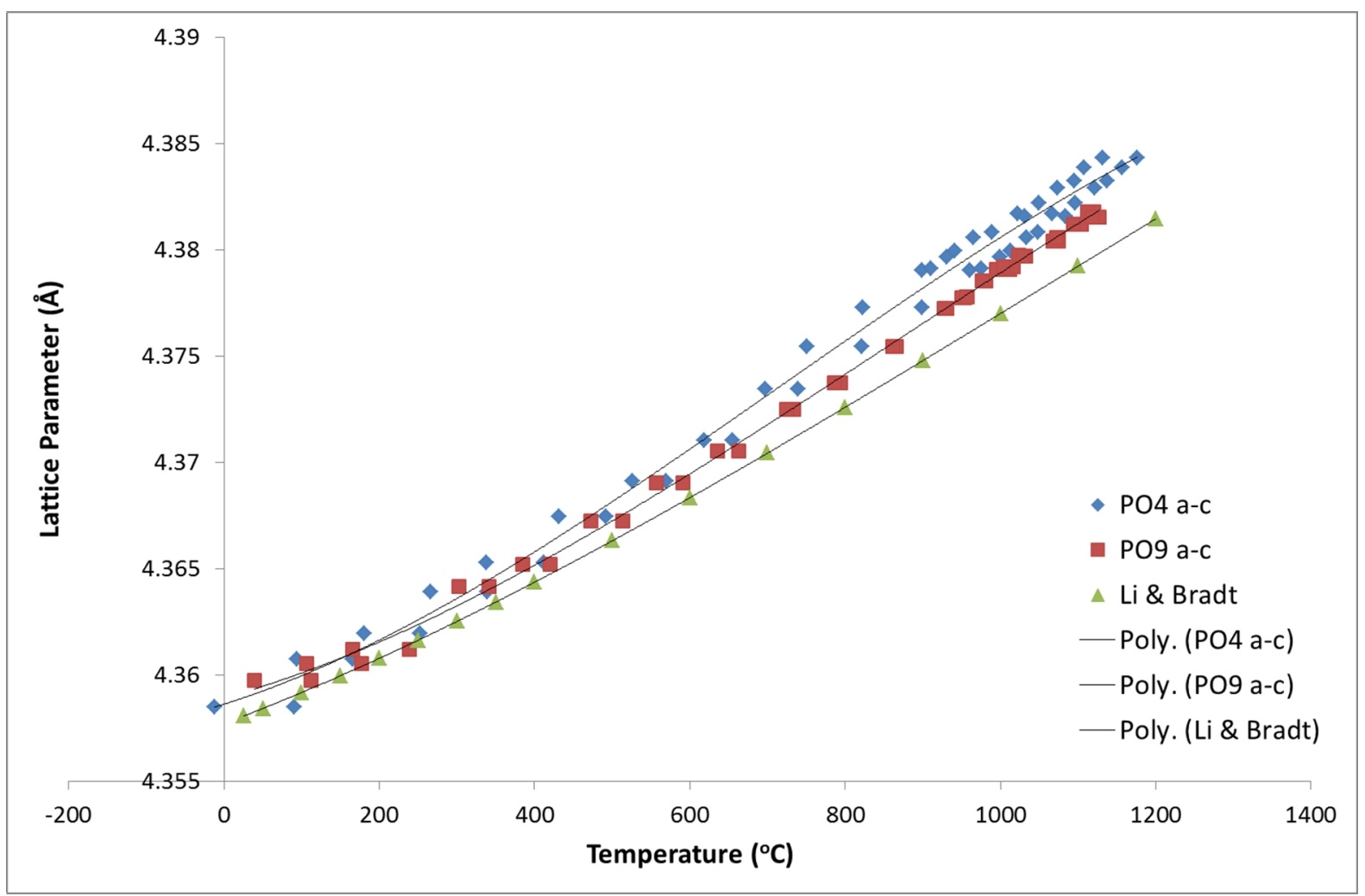

Figure 4. Temperature corrected $\mathrm{SiC}$ lattice constants for samples CR14-UP shells (squares), CR14 TRISO particles (triangles) and G102 TRISO particles (diamonds). These are compared with the data of Li and Bradt [5].

The corrected thermal expansion data for the CR14-UP samples are fitted to $3^{\text {rd }}$ order polynomials as a function of temperature in Celsius and are given as follows:

Sample CR14-UP shells:

$\mathrm{a}=-4.824295 \times 10^{-14} \mathrm{~T}^{3}+6.124798 \times 10^{-9} \mathrm{~T}^{2}+1.438000 \times 10^{-5} \mathrm{~T}+4.359782$

$R^{2}=0.9997$

Sample CR14-UP TRISO particles:

$\mathrm{a}=-2.962895 \times 10^{-12} \mathrm{~T}^{3}+9.692374 \times 10^{-9} \mathrm{~T}^{2}+1.379844 \times 10^{-5} \mathrm{~T}+4.357868$

$R^{2}=0.9995$

Sample G102 TRISO particles ( $4^{\text {th }}$ order polynomial):

$\mathrm{a}=8.378424 \times 10^{-15} \mathrm{~T}^{4}-1.671443 \times 10^{-11} \mathrm{~T}^{3}+1.624762 \times 10^{-8} \mathrm{~T} 2+1.337290 \times 10^{-5} \mathrm{~T}+4.357790$

$R^{2}=0.9996$ 
The lattice constant expansion of $\mathrm{SiC}$ with temperature for samples 4 and 5 is given in Figure 5. With these two samples there is a significant difference between the temperatures as determined by the alumina a-axis and c-axis dimensions. This is reflected in the figure, and the best fits between the data for the two samples are shown. The reasons for the poor correspondence is probably due to insufficient sample on the heating strips, giving poor peak intensities, as well as a course particle size of the alumina due to insufficient grinding. These factors affect the peak profiles, and therefore the lattice constants of alumina. Significant differences in the sample temperature as calculated from the refined a-axis and c-axis data of alumina are the result. The quality of the data is also reflected in the higher correlation constants.

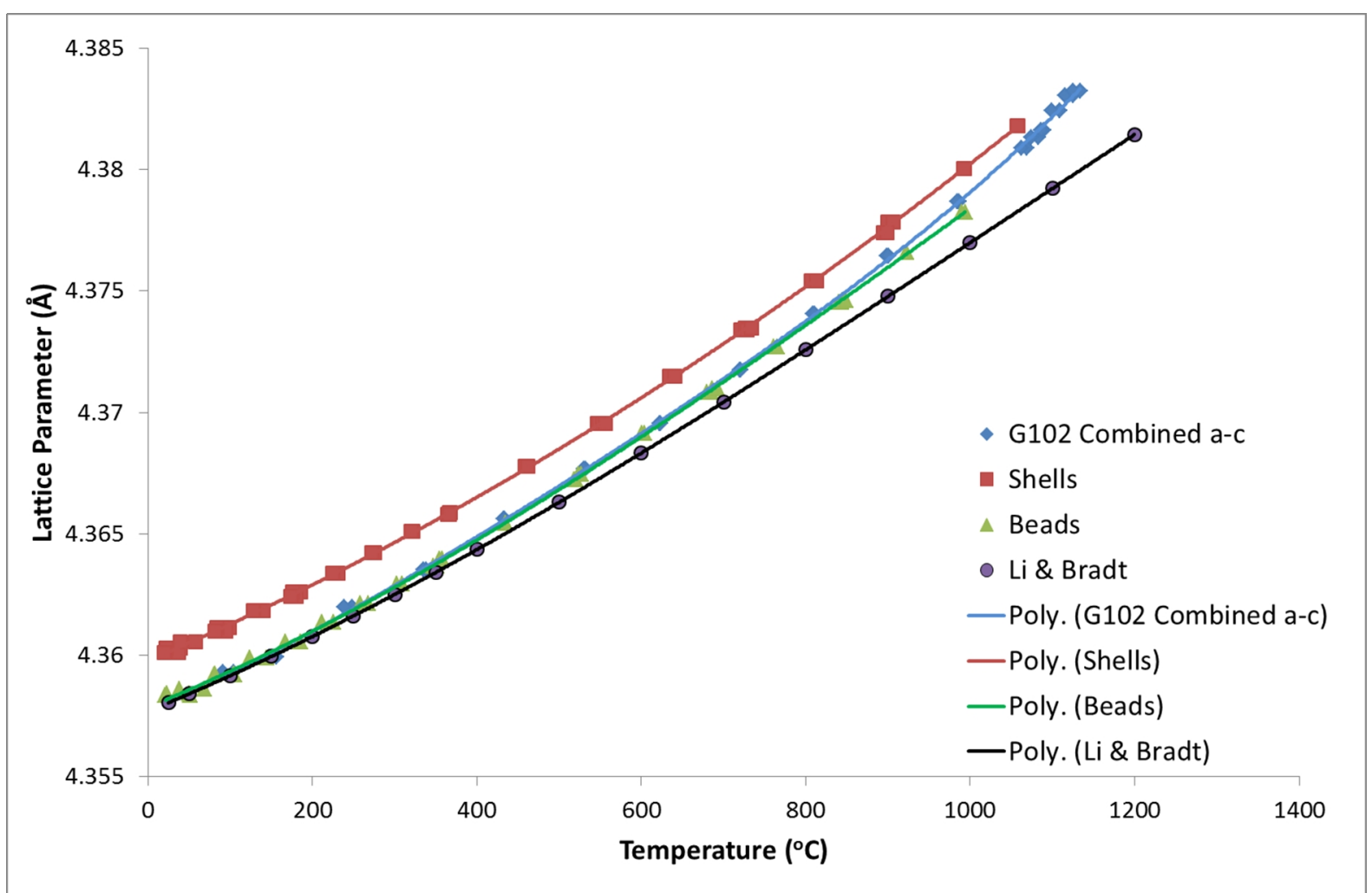

Figure 5. Temperature corrected SiC lattice constants for samples PO4 (diamonds) and PO9 (squares), both of TRISO particles. These are compared with the data of Li and Bradt [5].

The corrected thermal expansion data for the CR14 samples are fitted to $3^{\text {rd }}$ order polynomials and are given as follows:

Sample PO4 TRISO particles:

$\mathrm{a}=-9.267326 \times 10^{-12} \mathrm{~T}^{3}+1.970903 \times 10^{-08} \mathrm{~T}^{2}+1.151735 \times 10^{-05} \mathrm{~T}+4.358616$

$R^{2}=0.992$

Sample PO9 TRISO particles:

$\mathrm{a}=-6.241152 \times 10^{-12} \mathrm{~T}^{3}+1.605223 \times 10^{-08} \mathrm{~T}^{2}+1.018678 \times 10^{-05} \mathrm{~T}+4.358909$

$R^{2}=0.998$ 


\subsection{Thermal expansion coefficient results}

The corrected $\mathrm{SiC}$ unit cell dimensions were recalculated based on the temperature corrected curve for each sample. The temperature range used is chosen to be the same as the original experimental increments (i.e. $25^{\circ} \mathrm{C}$ up to $1200^{\circ} \mathrm{C}$ ). These values were then used to calculate the linear thermal expansion coefficients of $\mathrm{SiC}$ according to equation 8 below, assuming one-dimensional length change with temperature. The thermal expansion coefficient was calculated using the derivatives of figure 5 .

$\alpha_{L}=\frac{d(\ln L)}{d T} \approx \frac{1}{L_{0}} \cdot \frac{d L}{d T}$

with $L$ and $L_{0}$ the $\mathrm{SiC}$ lattice parameter values at temperature and at room temperature respectively. Each point of the thermal expansion coefficients is therefore the derivative of the best fit curve of the a-axis and c-axis $\mathrm{Al}_{2} \mathrm{O}_{3}$ corrected $\mathrm{SiC}$ thermal expansion curves. The thermal expansion coefficients for the first three samples are shown in Figure 6. These are deemed to the most accurate because of the consistency of the data, which includes both heating and cooling data, as well as the a-axis and c-axis temperature corrections which should not differ appreciably.

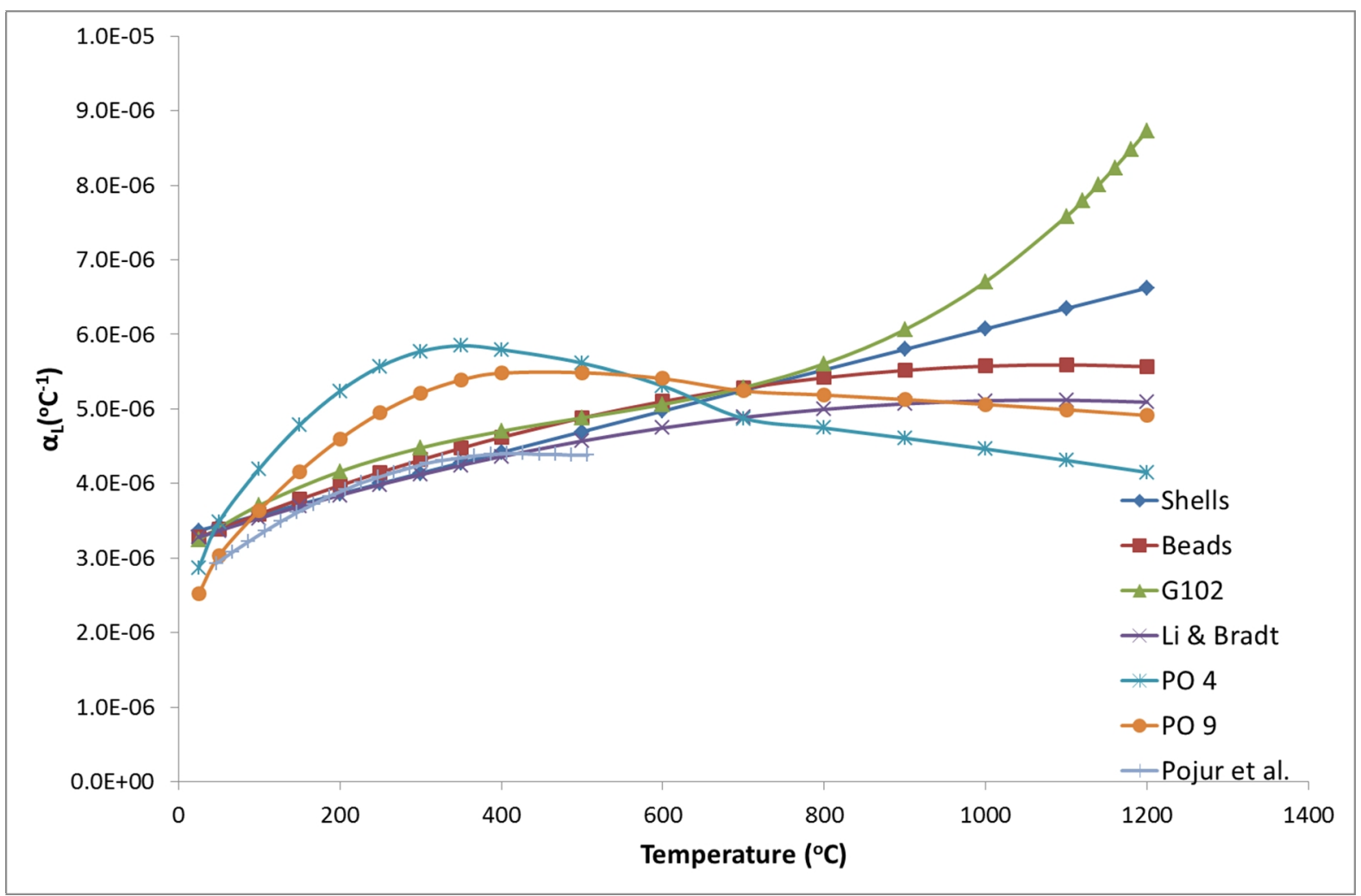

Figure 6 Linear thermal expansion coefficients of samples CR14-UP shells, CR14-UP TRISO, G102, PO4 and PO9 as compared to those of Li and Bradt [5] and Pojur et al.[10].

The linear expansion coefficients of sample CR14-UP shells follow a strictly linear trend over the whole temperature range in spite of the fact that it is the derivative of a $3^{\text {rd }}$ order polynomial. The coefficients can be described as a function of temperature $\left({ }^{\circ} \mathrm{C}\right)$ : 
$\alpha_{11}=2.7705 \times 10^{-09} \mathrm{~T}+3.3047 \times 10^{-06}\left({ }^{\circ} \mathrm{C}^{-1}\right)$

The coefficients of the CR14-UP TRISO sample are similar to those of Li and Bradt [5], but are increasingly diverging at higher temperatures. The expansion coefficients are described by the second order polynomial:

$\alpha_{11}=-2.0395 \times 10^{-12} \mathrm{~T}^{2}+4.4479 \times 10^{-9} \mathrm{~T}+3.1661 \times 10^{-6}\left({ }^{\circ} \mathrm{C}^{-1}\right)$

The coefficients of sample G102 are very close to those of sample CR14 up to $800^{\circ} \mathrm{C}$ but diverge sharply at higher temperatures. The reason for this is not apparent, since the temperature corrections derived from the alumina a- and c-axes correspond to within 6 $15^{\circ} \mathrm{C}$. This could be due to residual stress affects the thermal expansion in that annealing is commencing already at $800^{\circ} \mathrm{C}$, resulting in an increased lattice parameter at higher temperatures. The coefficients are best described by a $3^{\text {rd }}$ order polynomial:

$\alpha_{11}=7.6888 \times 10^{-15} \mathrm{~T}^{3}-1.1504 \times 10^{-11} \mathrm{~T}^{2}+7.4551 \times 10^{-9} \mathrm{~T}+3.0680 \times 10^{-6}\left({ }^{\circ} \mathrm{C}^{-1}\right)$

The coefficients of sample PO4 are described by a second order polynomial given by:

$\alpha_{11}=-6.3789 \times 10^{-12} \mathrm{~T}^{2}+9.0441 \times 10^{-09} \mathrm{~T}+2.6425 \times 10^{-06}\left({ }^{\circ} \mathrm{C}^{-1}\right)$

While the PO9 coefficients are described by a second order polynomial given by:

$\alpha_{11}=-4.2954 \times 10^{-12} \mathrm{~T}^{2}+7.3652 \times 10^{-09} \mathrm{~T}+2.3370 \times 10^{-06}\left({ }^{\circ} \mathrm{C}^{-1}\right)$

PO 9 underestimates the thermal expansion coefficient at low temperatures, but is comparable to previously published data at higher temperatures. Sample PO4 deviated significantly from all other curves and the shape becomes almost parabolic. It does initially resemble the result of Pojur et al.[10] from room temperature but overestimates subsequently. The reason for the deviation is thought to be related to the assumptions made when calculating the linear thermal expansion coefficient. Firstly, the relationship of equation 8 holds provided conditions of constant pressure exist. Inside a TRISO particle this is unlikely to be the case since it acts as a miniature pressure vessel. Sample PO4 had half the SiC thickness of PO9 and this is thought to play a role. Secondly, it is known that these particular samples contained small amounts of other polytypes (mainly $6 \mathrm{H}$ ) in addition to the $3 \mathrm{C}$ polytype as has been reported in a previous study [17]. It is however known that the thermal expansivity of $\mathrm{SiC}$ is significantly dependent on its crystal structure. The hexagonal $\mathrm{SiC}$ crystal exhibits anisotropic behaviour in thermal expansion between the a-axis and c-axis $[18,19]$. This accounts for the deviations observed.

The lattice constant expansion curve for the ground, disaggregated shells of sample CR14 TRISO coated particles follow a different thermal expansion curve than that of the TRISO particles themselves. In addition, the room temperature lattice constants of the two differ appreciably. Assuming that this is a real effect and that diffraction of the alumina standard and the SiC TRISO particles originated from the same sample position, then the $\mathrm{SiC}$ in the TRISO particles must be under compressive stress. This can be calculated from the uniaxial strain of $0.046 \%$ using the Elastic constants of $\mathrm{SiC}$. The residual compressive stress is determined as $304 \mathrm{KPa}$. This is in qualitative agreement with the findings of a Raman study of CVD deposited $\mathrm{SiC}$ by $\mathrm{Lu}$ and Leu [14] who also established that the $\mathrm{SiC}$ is under 
compressive residual stress. This needs to be investigated further using well characterised samples.

\section{Summary}

As can be seen from Figure 3, the data for the thermal expansion of the SiC of the CR14-UP disaggregated shells, CR14-UP TRISO particles and G102 are reliable in that derived temperatures correspond closely both for heating and cooling data. Also, the temperatures derived from the alumina a- and c-cell constants differ only by 18,30 and $13^{\circ} \mathrm{C}$ respectively. These are also reflected in the correlation coefficients. For samples PO4 and PO9 the data are considered to be less reliable because the derived temperatures (room temperature) from the alumina a and c cell constants differ by $100^{\circ} \mathrm{C}$ and $72^{\circ} \mathrm{C}$ respectively for the two samples. With regard to the thermal expansion of the $\mathrm{SiC}$, the following can be summarised:

The disaggregated shells from the CR14-UP TRISO coated particles follow a different trend than those of the TRISO coated particles themselves and their expansion coefficient follows a strictly linear trend over the measured temperature range. This linear expansion coefficient is given by the formula:

$$
\alpha_{11}=2.7705 \times 10^{-09} \mathrm{~T}+3.3047 \times 10^{-06}\left({ }^{\circ} \mathrm{C}^{-1}\right)
$$

The expansion of the TRISO particles in samples CR14-UP and G102 are almost coincident and differ only slightly at the highest temperature. Their linear expansion coefficients however diverge markedly at higher temperatures. This shows that the coefficients derived from differentiating the polynomials are very sensitive, reflecting small changes in slope. This sensitivity is further reflected by the behaviour of sample PO4 which deviates greatly from all other results. Sample PO9 only deviates at low temperatures.

The difference in thermal expansion coefficients of the different samples cannot be explained using the present data, but it can be commented that each of the curves determined in this study qualitatively seem to follow a similar curve to those in the literature, with the exception of PO4. See the summary and Figure by Li and Bradt [5]. Perhaps differences in residual stress could be reflected in these differences.

\section{References}

[1] J.J. Powers, B.D. Wirth B.D, Journal of Nuclear Materials 405 (2010) 74-82.

[2] L. Snead, T. Nozawa, Y. Katoh, T. Byun, S. Kondo, D. Petti, Journal of Nuclear Materials 371 (2007) 329377.

[3] PBMR, http://www.pbmr.co.za/contenthtml/pictureFX/imgcache/20051117 FuelElemDesCom.jpg, $(2006 / 08 / 18)$

[4] W.F. Knippenberg, Philips Research Report 18 (1963) 161-274.

[5] Z. Li, R.C. Bradt, Journal of the American Ceramic Society 70 [7] (1987) 445-448.

[6] K Becker, Zeitschrift für Physik 40 (1926) 37. 
[7] T.A. Taylor, R.M. Jones; in: J.R. O'Connor, J. Smiltens (Eds.), Silicon Carbide, a High-Temperature Semiconductor, Pergamon, Oxford, 1960, pp 147.

[8] D. Clark, D. Knight, Royal Aircraft Establishment, Technical Report RAE-TR-65049 (1965).

[9] H. Suzuki, T. Iseki, M Ito, Journal of Nuclear Materials 48 (1973) 247.

[10] A.F. Pojur, B. Yates, B.T. Kelly, Journal of Physics D 5 (1972) 1321.

[11] P. Popper, I. Mohyuddin, in: P. Popper (Ed.); Special Ceramics 1964, Academic Press, London, 1965, pp 45.

[12] R.J. Price, Journal of the American Ceramic Society Bulletin 48 (1969) 859.

[13] K. Niihara, Ceramic Bulletin 63 [9] (1984).

[14] Y.M. Lu, I.C. Liu, Thin Solid Films 377-378 (2000) 389-393.

[15] TOPAS Version 3.0, GmbH; Karlsruhe, West Germany (2003-2005).

[16] Y.S. Touloukian, R.K. Kirby, R.E. Taylor, T.Y.R. Lee, Thermophysical Properties of Matter 13 (1977) 176-185.

[17] J.P.R. de Villiers, Roberts J., N. Ngoepe, A. Tuling, Journal of Engineering for Gas Turbines and Power 131 (2009) 062904-1- 062904- 7.

[18] Z. Li, R.C. Bradt, Journal of Applied Physics 60 (1986) 612.

[19] Z. Li, R.C. Bradt, Journal of the American Ceramic Society 69 (1986) 863. 